\title{
Current Approaches to the Management of Infection in Cystic Fibrosis
}

\author{
J. Stuart Elborn
}

Published online: 25 June 2013

(c) Springer Science + Business Media New York 2013

\begin{abstract}
Bacterial infection is the primary initiator and driver of inflammation and lung injury in the airways of people with cystic fibrosis. Infection begins early in life and over time becomes chronic in many patients. Pseudomonas aeruginosa is the dominant pathogen in chronic infection and is associated with an accelerated decline in lung function, more frequent exacerbations, and reduced survival compared to people with no Gram-negative infection. Antibiotic eradication therapy is effective in delaying chronic infection with $P$. aeruginosa and can be employed repeatedly to new infections. When chronic infection develops, long-term inhaled antibiotics and azithromycin therapies reduce exacerbations, improve QoL, and may impact survival. Pulmonary exacerbations driven by infection and inflammation are associated with decline in lung function and reduced survival. Optimal therapy for these requires multiple antibiotics and close assessment of response. A number of other bacteria such as Staphylococcus aureus, Stenotrophomonas maltophilia, Achromobacter spp. and nontuberculous mycobacteria are an increasing problem in $\mathrm{CF}$ infection and bring new challenges to therapy.
\end{abstract}

Keywords Cystic fibrosis - Infection - Pseudomonas aeruginosa $\cdot$ Antibiotics

\section{Introduction}

Cystic fibrosis remains the most common life-shortening autosomal recessive disorder in Western European communities. CF is not exclusive to Western Europeans, but

J. S. Elborn (两)

Centre for Infection and Immunity, Queens University, Health Sciences Building, 97 Lisburn Road, Belfast BT9 7AE, UK

e-mail: s.elborn@qub.ac.uk occurs at a significantly higher prevalence among white than in African and Asian populations. It is estimated that there are around 30,000 people with cystic fibrosis in the USA and around 35,000 in Europe [1]. Over 2,000 autosomal recessive mutations have been described of the cystic fibrosis transmembrane regulator protein. Many of these are private mutations occurring in single families, and for some it is not clear if they are disease-causing. A recent major effort by a group in Johns Hopkins has produced a robust online database of mutations based on international registry data on mutations that are disease causing and the associated phenotypes [2].

Cystic fibrosis disease is caused by a dysfunctional cystic fibrosis transmembrane regulator protein which is primarily a chloride ion channel expressed in epithelial cells [3]. The primary action of this channel is chloride ion transport, but it also negatively controls sodium transport through the epithelial sodium channel $(\mathrm{ENaC})$. The CFTR and $\mathrm{ENaC}$ channels control the hydration of airway surface liquid which is key to mucociliary clearance $[4,5 \bullet \cdot$. CFTR is also a bicarbonate transporter and may be important in regulating the $\mathrm{pH}$ of airway surface liquid and directly affect the function of innate immune peptides [6••].

People with cystic fibrosis generally develop infection early in life [7]. This is associated with a neutrophil-mediated inflammatory response which is partially effective in phagocytosing bacteria [8••, 9]. However, with repeated episodes of infection in the milieu of reduced mucociliary clearance, bacteria have the opportunity to proliferate and form biofilms, and inflammation in the airway becomes chronic and self-enduring [10]. Proteases and oxidants are released from neutrophils which are frustrated as they cannot phagocytose bacteria protected by biofilms. These proteases and oxygen radicals impair innate immune system functions, further impairing phagocytosis [9]. The major airways, small 
bronchi and alveoli are damaged in this process, resulting in airway wall thickening and bronchiectasis with dilation of medium and small airways [8••]. These proteases also damage alveolar tissue and result in destruction of gas exchanging membranes.

Some studies have suggested that epithelial and possibly immune cells in cystic fibrosis have an augmented inflammatory response to pathogens. This is not entirely determined, and while this might be important in early infection, in established infection there is such a high load of bacteria that this is unlikely to be a major factor.

\section{Bacteriology of Cystic Fibrosis}

The bacteria isolated from airways secretions from people with cystic fibrosis (Fig. 1) come from several distinct genera. Early in life Staphylococcus aureus, either methocilliin resistant (MRSA) or sensitive (MSSA), dominate the flora, however Haemophilus influenzae, Stenotrophomonas maltophilia and a range of other Gram-negative bacteria can also cause infection. Into the second decade, Pseudomonas aeruginosa becomes established as a chronic infection in many young people. This is now aggressively treated with eradication therapy and the prevalence of Pseudomonas in children is steadily reducing [12••]. Many $\mathrm{CF}$ centres now have a prevalence of less than $10 \%$ of those under 18 with chronic $P$. aeruginosa infection. Other troublesome Gram-negative bacteria also play an important role. Bacteria from the Burkholderia cepacia complex, most particularly Burkholderia cenocepacia, Burkholderia multivorans and Burkholderia dolosa have all been associated with outbreaks [13]. These organisms are associated with constitutive resistance to most antimicrobial agents, have increased virulence, and in the case or B. cenocepacia or B. dolosa, are associated with reduced survival [14]. Other Burkholderia species such as B. gladiolii can also cause airway infection. Achromobacter are an increasing challenge in the $\mathrm{CF}$ airway and may be an opportunist pathogen in patients who have had a lot of antibiotic therapy. It was thought until recently that Achromobacter xyloxidans was the infecting agent in the majority of patients but recent genomic studies have indicated that a wide range of species are involved [15, 16]. S. maltophilia is also constitutively resistant to many antibiotics and is associated with generally poor outcomes, and present significant challenges in terms of treatment [17].

\section{The Airway Microbiome in Cystic Fibrosis}

The appreciation that microbes are present in many niches in the healthy human body has been driven by application of molecular approaches to the identification of microorganisms [18]. In cystic fibrosis, genomic approaches using terminal restriction fragment length polymorphism (T-RFLP) to explore bacterial population diversity, and more recently pyrosequencing, indicate that the airways microbiology is highly complex. Such complexity presents many new challenges in terms of how treatment is considered. Studies have demonstrated that in many patients over 100 different taxa can be identified using pyrosequencing approaches indicating a significant diversity of bacteria $[19,20]$. A surprising number of bacteria identified in these studies are anaerobes which are present in significant numbers by culture and pyrosequencing methods. The common genera in these studies identified are Prevotella, Veilonella, Gemella and Rothia species [21, 22]. These bacteria are common in the upper airways but often not in the high numbers identified in sputum. The relationship of this diverse microbiota and the dominant infecting organisms such as $S$. aureus, $P$. aeruginosa and B. cepacia complex organisms is still unclear. However it is highly likely that these organisms interact through quorum sensing mechanisms and may modify virulence, inflammation and susceptibility to antibiotics.

\section{Dominant Pathogens}

There has been interesting new data on infection with $S$. aureus published in the last 5 years $[23,24]$. It is now agreed that prophylactic antistaphylococcal antibiotic therapy is ineffective, and there are significant concerns that it may promote earlier infection with $P$. aeruginosa [24]. Methicillin resistant $S$. aureus (MRSA) is becoming an increasing challenge in paediatric centres [23]. The prevalence of this organism can be as high as $35 \%$ and represents cross infection and therapeutic challenges in both infection control and therapy. MRSA organisms found in the sputum of people with CF usually reflect the common MRSA organisms prevalent in local institutions.

It has also become evident that $P$. aeruginosa is an orgnaism highly adapted to the niche of the airways in CF. Under stressful conditions found in the CF airway, Pseudomonas evolves a range of genetic and phenotypic changes that allow it to adapt and prosper in the $\mathrm{CF}$ airways [10]. This includes considerable diversity in the ability to develop antimicrobial resistance. A shift to increased expression of genes in the algU regulon results in downregulation of metabolism, motility and virulence and upregulation of genes controlling membrane permeability and efflux [10]. The frequent use of antibiotics is a further driver of resistance. 


\subsection{Lung infections in 2011}

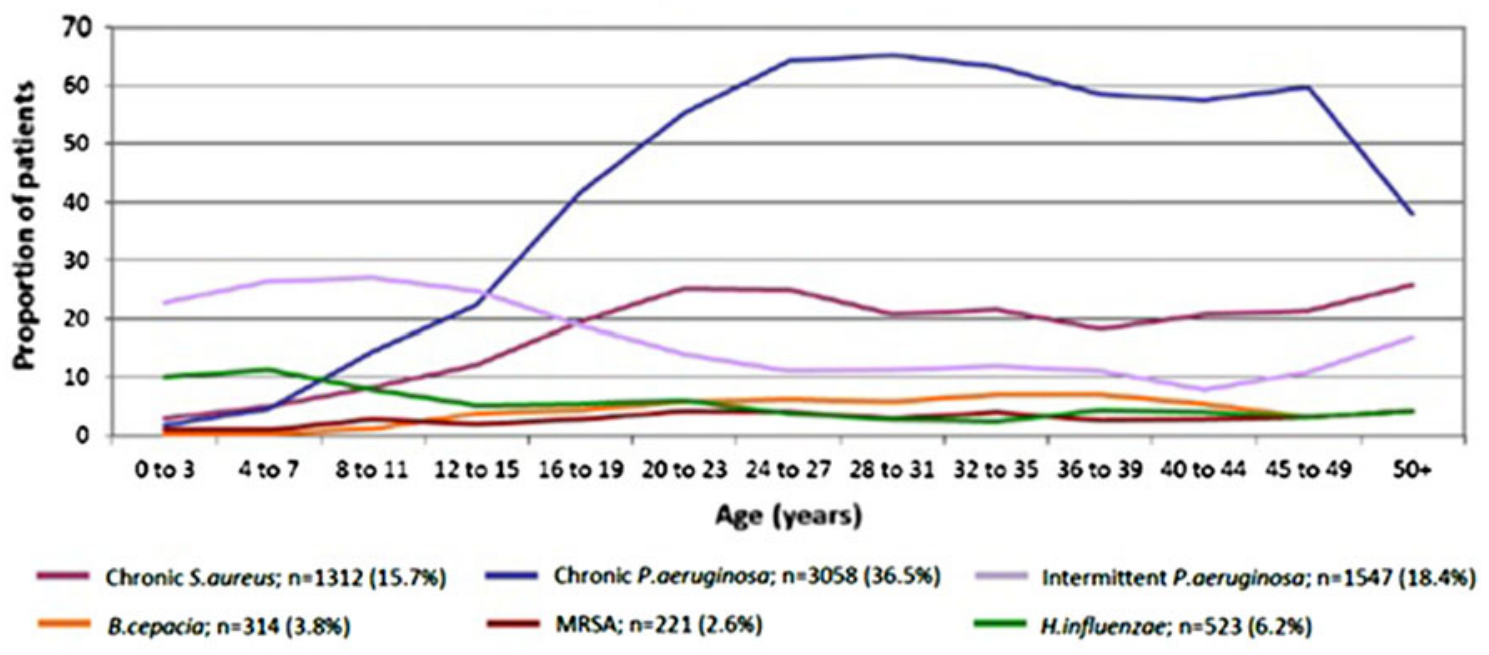

Fig. 1 Infection prevalence by age in people with CF in the UK for 2011 [11]

\section{Infection Control}

Patient to patient transmission of bacteria in cystic fibrosis has been a major area of concern since the late 1980s, when the first outbreak of infection with what we now know to be B. cenocepacia occurred in Canada [25]. This organism is likely to have been transmitted during summer camps which were encouraged at that time to help increase the confidence and independence of young people with cystic fibrosis. These camps were attended by people with CF from the UK and Ireland and may have been the source for index cases in CF centres in the British Isles [26-28]. A number of important studies demonstrated the clonality of this organism and its ability to spread from patient to patient. In the case of B. cenocepacia, transmissibility is associated with virulence, which in many patients is rapidly lethal. The appreciation of this in the 1990s has resulted in very stringent infection control in $\mathrm{CF}$ centres throughout the world [29].

It is also clear that some strains of $P$. aeruginosa are also transmissible [30, 31]. Important studies in Europe and Australia have identified clonal strains, and it is likely that there has been patient to patient transmission [32]. The association with virulence is much less clear with transmissible strains of Pseudomonas. No study has definitively demonstrated a reduction in survival, though some studies suggest an increased morbidity with pulmonary exacerbations and hospital admissions. Most recently, two studies have suggested that Mycobacterium abscessus, particularly the subspecies $M$. massiliense, can be spread from patient to patient $[33,34 \bullet \cdot]$. Nontuberculous mycobacterial infection, particularly with $M$. abscessus complex strain, is becoming more common in the cystic fibrosis population, and this study adds further concerns about infection control as it occurred in a centre with excellent infection control aimed at preventing transmission of $P$. aeruginosa and other Gram-negative bacteria [34••].

It is clear from the above that infection control needs to be considered in all CF centres and this optimally requires no contact between patients with private rooms during hospital admission, and appropriate arrangements for outpatient clinics to minimise patient to patient contact. Meticulous infection control measures, including hand hygiene and proper cleansing of equipment (including lung function machines and stethoscopes in the outpatient setting), are also important. Infection control issues can be very problematic within families when one sibling with cystic fibrosis acquires, for example, B. cenocepacia or $B$. multivorans infection and has another sibling with CF who does not have this organism. This can result in considerable social and emotional challenges for families.

\section{Microbial Surveillance and Diagnosis}

The accurate identification of bacteria in the sputum of people with cystic fibrosis is critically important. This is primarily to ensure that appropriate antibiotics are used to treat infection in the airways and secondly to provide surveillance for new organisms and potentially cross infection. Where possible, sputum samples are taken at regular outpatient and inpatient hospital attendances. When sputum is not available, which is increasingly common with children with good lung function, cough swabs can be used though these are of less value than sputum [35]. 
The sputum cough swabs, or in some cases bronchiolar lavage, needs to be carefully cultured with appropriate selective media to enable the identification of the appropriate range of organisms [35]. The identification of bacteria is usually undertaken through an automated biochemical testing system such as Vitek or API20NE, but these systems are not entirely accurate particularly for less common Gram-negative species. Susceptibility testing should be undertaken for all the common species. This is helpful in determining the appropriate antibiotic to use in many cases. However, there is evidence to suggest that once chronic $P$. aeruginosa infection has become established in the airways that antimicrobial sensitivity testing is unhelpful and in some cases inaccurate [12••, 36, 37]. Synergy testing to determine optimal antibiotic choice has also been shown not to be of benefit and does not appear to affect the prescription of antibiotics or the outcome of treatment [38].

\section{Antibiotic Treatment for Cystic Fibrosis}

\section{Staphylococcus aureus}

For some time there has been debate around using prophylactic anti-staphylococcal therapy, particularly in children with cystic fibrosis [39]. There is no definitive study yet to support this. A recent meta-analysis of studies there is a suggestion that long-term prophylaxis is associated with higher isolation rate of $P$. aeruginosa [39]. This practice is still employed in a few countries, but in general prophylactic therapy is not used. Treatment of $S$. aureus is straightforward when it is sensitive to flucloxacillin or methicillin, when conventional semisynthetic antistaphylococcal penicillins (flucloxacillin, oxacillin, nafcillin) can be used. However, MRSA has become an increasingly prevalent infection in CF Centres. A positive culture of MRSA is associated with lower lung function and higher rates of hospital admission and antibiotic usage [40]. There has also been an association with an increased mortality demonstrated from a registry study [23]. There is a growing consensus that MRSA should be eradicated. and there are a number of current and proposed clinical trials which are attempting to determine the most effective regime. A small case series using rifampicin, fusidic acid, vancomycin, vibramycin, co-trimoxazole and linezolid, usually in a combination of two drugs, have demonstrated eradication, but it is not clear which of these is most effective.

Haemophilus influenzae

Haemophilus influenzae is a reasonably common isolate particularly in children and teenagers with $\mathrm{CF}$ and may be co-cultured with other bacteria. It is usually sensitive to amoxicillin/clavulanate and doxycycline which are appropriate antibiotics for this organism [12••].

Pseudomonas aeruginosa

Pseudomonas aeruginosa represents the most difficult and challenging bacteria in the $\mathrm{CF}$ airways and accounts for a considerable amount of the morbidity and may also drive decrease in lung function and associated reduction in survival $[12 \bullet \cdot]$. Antibiotic treatment directed against $P$. aeruginosa can be considered in three specific areas: antibiotic eradication therapy (AET), treatment of pulmonary exacerbations and treatment of chronic P. aeruginosa infection.

\section{Antibiotic Eradication Therapy}

There is a very compelling rationale for antibiotic eradication therapy in people infected with $P$. aeruginosa for the first time or intermittently following previous successful eradication treatments. This was first described using a combination of inhaled colistin and oral ciprofloxacin, but subsequently has also been shown to be efficacious with inhaled tobramycin alone [40, 41]. Two small studies have compared these respective regimes and not identified any significant difference in the eradication rate $[42,43]$. We have no data yet to determine if eradication of $P$. aeruginosa improves lung function and survival. However, it is highly likely that postponing chronic infection with $P$. aeruginosa for as long as possible is likely to be helpful in improving both of these outcomes. With repeated episodes of eradication therapy it is likely there will be more failures to eradicate, and a recent consensus conference has suggested an algorithm to maximise the success of antibiotic eradication therapy (AET) (Fig. 2).

\section{Treatment of Chronic $P$. aeruginosa Infection}

The majority of people with cystic fibrosis still have chronic infection with $P$. aeruginosa. Long-term treatment with inhaled antibiotics has been demonstrated to improve pulmonary function and quality of life and to increase the time between and thus decrease the frequency of pulmonary exacerbations $[12 \bullet \bullet, 44]$. Tobramycin and colistin have both been licensed for this purpose for some time, though the data for tobramycin is considerably more compelling than for olistin [45]. Recently aztreonam lysine has been approved and has shown noninferiority to alternate tobramycin. One of the challenges with inhaled antibiotic therapy is that tobramycin is licensed to be used on alternate 
Fig. 2 The proposed Artimeno algorithm for failure to clear new isolation of $P$. aeruginosa in CF. Reproduced with permission from: Döring G, et al. Treatment of Lung Infection in Patients with Cystic Fibrosis: Current and Future Strategies. J CYST FIBROS. 2012;11(6):461-479) [12••]

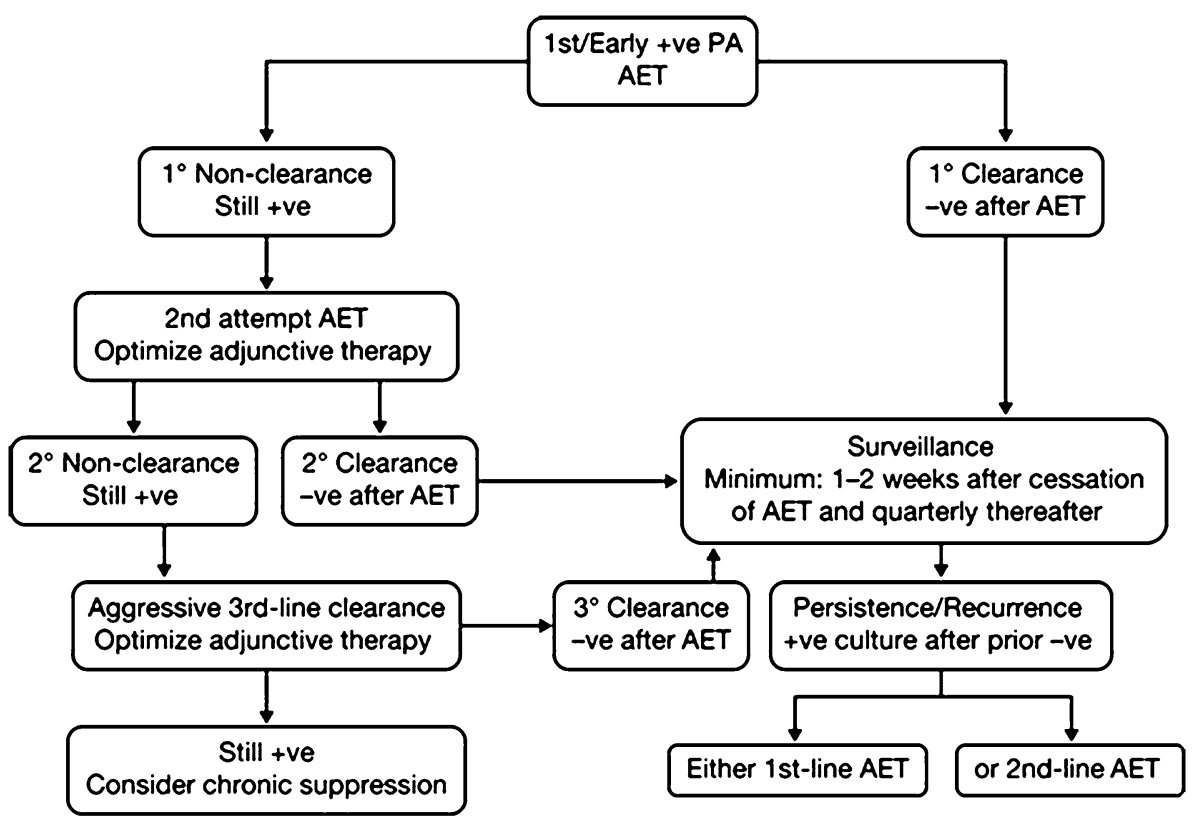

months to reduce the development of resistance. However, on the off month many patients have more symptoms, and increasingly this off month is being filled with either treatment with colistin or aztreonam. It is not clear what might be the most effective cycling therapy for CF. Tobramyin and colistin are now both available as dry powder inhalers, which is likely to be helpful in terms of adherence as these require less time than nebulised therapy [46, 47]. Levofloxacin, ciprofloxacin and amikacin are all being developed as new antibiotics for use in cystic fibrosis [48-53].

\section{Exacerbations in People with Chronic Pseudomonas Infection}

Pulmonary exacerbations are very important events in people with cystic fibrosis [54]. Exacerbations are associated with an increase in symptoms and systemic markers of inflammation and often a reduction in lung function [55-57]. Pulmonary exacerbations are associated with accelerated declines in lung function and a number of recent studies also suggest they are associated with reduced survival. Preventing these pulmonary exacerbations is of utmost importance. This can be achieved by combinations of mucolytic therapies such as Dornase alpha and hypertonic saline, inhaled antibiotics as discussed above and regular macrolide therapy using azithromycin [45]. Azithromycin is thought to have a combination of antimicrobial and anti-inflammatory effects. However, despite these therapies which have good evidence from randomised controlled trials that they prevent exacerbations, many people with Pseudomonas have exacerbations [45].

Treating exacerbations with the appropriate antibiotics in addition to supportive therapy with increased airways clearance is critically important as up to a quarter of patients can fail to recover their lung function following these episodes. Antibiotic therapy is determined somewhat empirically although in vitro antimicrobial testing can be of some general value. However a number of small studies have suggested that knowing the resistance to bacteria does not improve outcomes [12••]. Intravenous antibiotic therapy can be successfully delivered in hospital and at home. There have been few efficacy or economic evaluations comparing these approaches [12••]. However, it is critically important that supportive therapy such as increased airways clearance, nutrition, and social support are provided for both hospital and home delivery of intravenous antibiotics. The duration of intravenous therapy is usually 10-14 days and persisting beyond 21 days with the same antibiotics is not recommended [12••].

\section{Antibiotic Treatment for Other Bacterial Pathogens}

A range of other Gram-negative bacteria are problematic in people with CF. There are a few case reports that these organisms can be eradicated although there is little consensus about what appropriate regimes should be used. Exacerbations are empirically using anti-pseudomonal antibiotic usually combined with tetracycline, co-trimoxazole and in the case of B. cepacia complex chloramphenicol $[17,58]$. Detailed guidelines for these organisms are available in the Cystic Fibrosis Trust Antibiotic 
Guidelines [58]. Treatment of nontuberculous mycobacteria (NTM) is also very challenging and based on American Thoracic Society Guidelines [59]. Recently, streptococci which are found in high numbers in CF sputum have been associated with pulmonary exacerbations and in some instances it may be helpful to treat [60].

\section{Resistance, Toxicity and Allergy}

Antimicrobial resistance is common in CF organisms and is of concern. This is particularly important, as people with cystic fibrosis born now are likely to live into their 50s and 60s and have an enormous lifetime exposure to antibiotics. Strategies to ensure effective treatment while minimising resistance need to be considered [58]. Antibiotics can also have accumulative toxicity in $\mathrm{CF}$, in particular the aminoglycosides have been associated with nephrotoxicity [61]. This is particularly an issue with gentamicin but accumulative doses of other aminoglycosides can impair renal function. Antibiotic allergy is also common in cystic fibrosis and does not easily fit into the classic definition. Desensitisation can be undertaken successfully [62].

\section{Conclusion}

The use of antimicrobial agents in the treatment of cystic fibrosis has been a key part of the improved outcomes in this condition. Understanding the complexity of airways infection and developing more effective approaches to treatment is still a very important aspect of CF care.

Disclosure J. Stuart Elborn declares that he has no conflict of interest.

Human and Animal Rights and Informed Consent This article does not contain any studies with human or animal subjects performed by any of the authors.

\section{References}

Papers of particular interest, published recently, have been highlighted as:

•. Of major importance

1. Salvatore D, Buzzetti R, Baldo E, Furnari ML, Lucidi V, Manunza D, Marinelli I, Messore B, Neri AS, Raia V, Mastella G. An overview of international literature from cystic fibrosis registries. Part 4: update 2011. J Cyst Fibros. 2012;11(6):480-93.

2. http://www.cftr2.org/.

3. Boucher RC. New concepts of the pathogenesis of cystic fibrosis lung disease. Eur Respir J. 2004;23(1):146-58. Review. PubMed PMID: 14738247.
4. Livraghi-Butrico A, Kelly EJ, Wilkinson KJ, Rogers TD, Gilmore RC, Harkema JR, Randell SH, Boucher RC, O'Neal WK, Grubb BR. Loss of Cftr function exacerbates the phenotype of $\mathrm{Na}(+)$ hyperabsorption in murine airways. Am J Physiol Lung Cell Mol Physiol. 2013;304(7):L469-80. doi:10.1152/ajplung.00150.2012. Epub 2013 Feb 1. PubMed PMID: 23377346; PubMed Central PMCID: PMC3627939.

5. • Button B, Cai LH, Ehre C, Kesimer M, Hill DB, Sheehan JK, Boucher RC, Rubinstein M. A periciliary brush promotes the lung health by separating the mucus layer from airway epithelia. Science. 2012; 337(6097):937-41. Important study showing how mucocilary clearance is very sensitive to osmotic pressure and how critical the normal hydration of peri-ciliary fluid and mucus is in the airway.

6. • Pezzulo AA, Tang XX, Hoegger MJ, Alaiwa MH, Ramachandran S, Moninger TO, Karp PH, Wohlford-Lenane CL, Haagsman HP, van Eijk M, Bánfi B, Horswill AR, Stoltz DA, McCray PB Jr, Welsh MJ, Zabner J. Reduced airway surface $\mathrm{pH}$ impairs bacterial killing in the porcine cystic fibrosis lung. Nature. 2012; 487(7405):109-13. Pivotal study which demonstrates the links between infection, neutrophil elastase and CT scan evidence of bronchiectasis in an outstanding prospective study of $C F$ infants.

7. Mott LS, Park J, Gangell CL, de Klerk NH, Sly PD, Murray CP, Stick SM; Australian Respiratory Early Surveillance Team for Cystic Fibrosis (AREST CF) Study Group. Distribution of Early Structural Lung Changes due to Cystic Fibrosis Detected with Chest Computed Tomography. J Pediatr. 2013 Jan 25.

8. •• Sly PD, Gangell CL, Chen L, Ware RS, Ranganathan S, Mott LS, Murray CP, Stick SM; the AREST CF Investigators. Risk Factors for Bronchiectasis in Children with Cystic Fibrosis. N Engl J Med. 2013 May 21. [Epub ahead of print] PubMed PMID:23692169. Pivotal study which demonstrates the links between infection, neutrophil elastase and CT scan evidence of bronchiectasis in an outstanding prospective study of CF infants.

9. Cohen TS, Prince A. Cystic fibrosis: a mucosal immunodeficiency syndrome. Nat Med. 2012;18:509-19.

10. Folkesson A, Jelsbak L, Yang L, Johansen HK, Ciofu O, Høiby $\mathrm{N}$, Molin S. Adaptation of Pseudomonas aeruginosa to the cystic fibrosis airway: an evolutionary perspective. Nat Rev Microbiol. 2012;10(12):841-51.

11. https://www.cysticfibrosis.org.uk/media/82506/CR_Annual_Data_ Report_2011_Jan_13.pdf.

12. •• Döring G, Flume P, Heijerman H, Elborn JS. Consensus Study Group. Treatment of lung infection in patients with cystic fibrosis: current and future strategies. J Cyst Fibros. 2012;11:461-79. Recent important consensus on use of antibiotics in $C F$.

13. Govan JR, Brown AR, Jones AM. Evolving epidemiology of Pseudomonas aeruginosa and the Burkholderia cepacia complex in cystic fibrosis lung infection. Future Microbiol. 2007;2: 153-64.

14. Kalish LA, Waltz DA, Dovey M, et al. Impact of Burkholderia dolosa on lung function and survival in cystic fibrosis. Am J Respir Crit Care Med. 2006;173:421-5.

15. Barrado L, Brañas P, Orellana MÁ, Martínez MT, García G, Otero JR, Chaves F. Molecular characterization of achromobacter isolates from cystic fibrosis and non-cystic fibrosis patients in Madrid, Spain. J Clin Microbiol. 2013;51(6):1927-30. doi:10.1128/JCM.00494-13. Epub 2013 Mar 27.

16. Spilker T, Vandamme P, Lipuma JJ. Identification and distribution of Achromobacter species in cystic fibrosis. J Cyst Fibros. 2013;12(3):298-301. doi:10.1016/j.jcf.2012.10.002. Epub 2012 Nov 7.

17. Waters V, Yau Y, Prasad S, et al. Stenotrophomonas maltophilia in cystic fibrosis: serologic response and effect on lung disease. Am J Respir Crit Care Med. 2011;183:635-40. 
18. Fodor AA, Klem ER, Gilpin DF, et al. The adult cystic fibrosis airway microbiota is stable over time and infection type, and highly resilient to antibiotic treatment of exacerbations. PLoS ONE. 2012;7:e45001.

19. Stressmann FA, Rogers GB, van der Gast CJ, et al. Long-term cultivation-independent microbial diversity analysis demonstrates that bacterial communities infecting the adult cystic fibrosis lung show stability and resilience. Thorax. 2012;67:867-73.

20. Zhao J, Schloss PD, Kalikin LM, et al. Decade-long bacterial community dynamics in cystic fibrosis airways. Proc Natl Acad Sci USA. 2012;109:5809-14.

21. Tunney MM, Field TR, Moriarty TF, et al. Detection of anaerobic bacteria in high numbers in sputum from patients with cystic fibrosis. Am J Respir Crit Care Med. 2008;177:995-1001.

22. Tunney MM, Klem ER, Fodor AA, et al. Use of culture and molecular analysis to determine the effect of antibiotic treatment on microbial community diversity and abundance during exacerbation in patients with cystic fibrosis. Thorax. 2011;66:579-84.

23. Dasenbrook EC, Checkley W, Merlo CA, et al. Association between respiratory tract methicillin-resistant Staphylococcus aureus and survival in cystic fibrosis. JAMA. 2010;303:2386-92.

24. Goss CH, Muhlebach MS. Review: Staphylococcus aureus and MRSA in cystic fibrosis. J Cyst Fibros. 2011;10(5):298-306.

25. Isles A, Maclusky I, Corey M, Gold R, Prober C, Fleming P, Levison H. Pseudomonas cepacia infection in cystic fibrosis: an emerging problem. J Pediatr. 1984;104(2):206-10.

26. Govan JR, Brown PH, Maddison J, Doherty CJ, Nelson JW, Dodd M, Greening AP, Webb AK. Evidence for transmission of Pseudomonas cepacia by social contact in cystic fibrosis. Lancet. 1993;342:15-9.

27. Jones AM, Govan JR, Doherty CJ, et al. Identification of airborne dissemination of epidemic multiresistant strains of Pseudomonas aeruginosa at a CF centre during a cross infection outbreak. Thorax. 2003;58:525-7.

28. Jones AM, Dodd ME, Webb AK. Burkholderia cepacia: current clinical issues, environmental controversies and ethical dilemmas. Eur Respir J. 2001;17:295-301.

29. Saiman L, Siegel J. Cystic Fibrosis Foundation Consensus Conference on Infection Control Participants. Infection control recommendations for patients with cystic fibrosis: microbiology, important pathogens, and infection control practices to prevent patient-to-patient transmission. Am J Infect Control. 2003;31(3 Suppl):S1-62.

30. Jones AM, Govan JR, Doherty CJ, et al. Spread of a multiresistant strain of Pseudomonas aeruginosa in an adult cystic fibrosis clinic. Lancet. 2001;358:557-8.

31. Aaron SD, Vandemheen KL, Ramotar K, et al. Infection with transmissible strains of Pseudomonas aeruginosa and clinical outcomes in adults with cystic fibrosis. JAMA. 2010;304:2145-53.

32. Kidd TJ, Ramsay KA, Hu H, Marks GB, Wainwright CE, Bye PT, Elkins MR, Robinson PJ, Rose BR, Wilson JW, Grimwood $\mathrm{K}$, Bell SC, ACPinCF Investigator Group. Shared Pseudomonas aeruginosa genotypes are common in Australian cystic fibrosis centres. Eur Respir J. 2013;41(5):1091-100.

33. Aitken ML, Limaye A, Pottinger P, Whimbey E, Goss $\mathrm{CH}$, Tonelli MR, Cangelosi GA, Dirac MA, Olivier KN, Brown-Elliott BA, McNulty S, Wallace RJ Jr. Respiratory outbreak of Mycobacterium abscessus subspecies massiliense in a lung transplant and cystic fibrosis center. Am J Respir Crit Care Med. 2012;15:185.

34. • Bryant JM, Grogono DM, Greaves D, Foweraker J, Roddick I, Inns T, Reacher M, Haworth CS, Curran MD, Harris SR, Peacock SJ, Parkhill J, Floto RA. Whole-genome sequencing to identify transmission of Mycobacterium abscessus between patients with cystic fibrosis: a retrospective cohort study. Lancet. 2013 May 4;381(9877):1551-60. This study demonstrates for the first time that $M$ abcessus complex NTMs can be transmitted from patient to patient.

35. Laboratory standards for processing microbiological samples from people with cystic fibrosis. Report of the UK Cystic Fibrosis Trust Microbiology Laboratory Standards Working Group. 1st Edition, Sept 2010. https://www.cysticfibrosis.org.uk/media/82034/ CD_Laboratory_Standards_Sep_10.pdf.

36. Gillham MI, Sundaram S, Laughton CR, Haworth CS, Bilton D, Foweraker JE. Variable antibiotic susceptibility in populations of Pseudomonas aeruginosa infecting patients with bronchiectasis. J Antimicrob Chemother. 2009;63(4):728-32. doi:10.1093/jac/ dkp007. Epub 2009 Feb 4.

37. Foweraker JE, Laughton CR, Brown DF, Bilton D. Comparison of methods to test antibiotic combinations against heterogeneous populations of multiresistant Pseudomonas aeruginosa from patients with acute infective exacerbations in cystic fibrosis. Antimicrob Agents Chemother. 2009;53(11):4809-15. doi:10.1128/ AAC.00269-09.

38. Aaron SD, Vandemheen KL, Ferris W, Fergusson D, Tullis E, Haase D, Berthiaume Y, Brown N, Wilcox P, Yozghatlian V, Bye P, Bell S, Chan F, Rose B, Jeanneret A, Stephenson A, Noseworthy M, Freitag A, Paterson N, Doucette S, Harbour C, Ruel M, MacDonald N. Combination antibiotic susceptibility testing to treat exacerbations of cystic fibrosis associated with multiresistant bacteria: a randomised, double-blind, controlled clinical trial. Lancet. 2005;366(9484):463-71.

39. Smyth AR, Walters S. Prophylactic anti-staphylococcal antibiotics for cystic fibrosis. Cochrane Database of Systematic Reviews 2012, Issue 12. Art. No.: CD001912. DOI: 10.1002/ 14651858.CD001912.pub2.

40. Dasenbrook EC, Merlo CA, Diener-West M, et al. Persistent methicillin-resistant Staphylococcus aureus and rate of FEV1 decline in cystic fibrosis. Am J Respir Crit Care Med. 2008; 178:814-21.

41. Proesmans M. Comparison of two treatment regimens for eradication of $\mathrm{P}$ aeruginosa infection in children with cystic fibrosis. J Cyst Fibros 2012; in press.

42. Taccetti G, Bianchini E, Cariani L, et al. Early antibiotic treatment for Pseudomonas aeruginosa eradication in patients with cystic fibrosis: a randomised multicentre study comparing two different protocols. Thorax 2012; Feb 29.

43. Valerius NH, Koch C, Høiby N. Prevention of chronic Pseudomonas aeruginosa colonisation in cystic fibrosis by early treatment. Lancet. 1991;338:725-6.

44. Ratjen F, Munck A, Kho P, Angyalosi G. ELITE Study Group. Treatment of early Pseudomonas aeruginosa infection in patients with cystic fibrosis: the ELITE trial. Thorax. 2010;65:286-91.

45. Mogayzel PJ Jr, Naureckas ET, Robinson KA, Mueller G, Hadjiliadis D, Hoag JB, Lubsch L, Hazle L, Sabadosa K, Marshall B. Pulmonary Clinical Practice GuidelinesCommittee. Cystic fibrosis pulmonary guidelines. Chronic medications formaintenance of lung health. Am J Respir Crit Care Med. 2013;187(7):689.

46. Schuster A, Haliburn C, Döring G, et al. Safety, efficacy and convenience of colistimethate sodium dry powder for inhalation (Colobreathe ${ }^{\circledR}$ DPI) in cystic fibrosis patients: a randomised study Thorax 2012; in press.

47. Konstan MW, Flume PA, Kappler M, et al. Safety, efficacy and convenience of tobramycin inhalation powder in cystic fibrosis patients: The EAGER trial. J Cyst Fibros. 2011;10:54-61.

48. Geller DE, Flume PA, Staab D, Fischer R, Loutit JS, Conrad DJ. Mpex 204 Study Group. Levofloxacin inhalation solution (MP-376) in patients with cystic fibrosis with Pseudomonas aeruginosa. Am J Respir Crit Care Med. 2011;183(11):1510-6.

49. Serisier DJ, Bilton D, De Soyza A, Thompson PJ, Kolbe J, Greville HW, Cipolla D, Bruinenberg P, Gonda I; the ORBIT-2 
investigators. Inhaled, dual release liposomal ciprofloxacin in non-cystic fibrosis bronchiectasis (ORBIT-2): a randomised, double-blind, placebo-controlled trial. Thorax. 2013 May 16. doi: 10.1136/thoraxjnl-2013-203207.

50. Okusanya OO, Bhavnani SM, Hammel J, Minic P, Dupont LJ, Forrest A, Mulder GJ, Mackinson C, Ambrose PG, Gupta R. Pharmacokinetic and pharmacodynamic evaluation of liposomal amikacin for inhalation in cystic fibrosis patients with chronic pseudomonal infection. Antimicrob Agents Chemother. 2009; 53(9):3847-54. doi:10.1128/AAC.00872-08.

51. King P, Lomovskaya O, Griffith DC, Burns JL, Dudley MN. In vitro pharmacodynamics of levofloxacin and other aerosolized antibiotics under multiple conditions relevant to chronic pulmonary infection in cystic fibrosis. Antimicrob Agents Chemother. 2010;54(1):143-8. doi:10.1128/AAC.00248-09.

52. Hoffman LR, Ramsey BW. Cystic fibrosis therapeutics: the road ahead. Chest. 2013;143(1):207-13.

53. Ramsey BW, Banks-Schlegel S, Accurso FJ, et al. Future directions in early cystic fibrosis lung disease research: an NHLBI workshop report. Am J Respir Crit Care Med. 2012;185:887-92.

54. Cohen-Cymberknoh M, Shoseyov D, Kerem E. Managing cystic fibrosis: strategies that increase life expectancy and improve quality of life. Am J Respir Crit Care Med. 2011;183:1463-71.

55. Parkins MD, Rendall JC, Elborn JS. Incidence and risk factors for pulmonary exacerbation treatment failures in patients with cystic fibrosis chronically infected with Pseudomonas aeruginosa. Chest. 2012;141:485-93.
56. Sanders DB, Bittner RC, Rosenfeld M, et al. Failure to recover to baseline pulmonary function after cystic fibrosis pulmonary exacerbation. Am J Respir Crit Care Med. 2010;182:627-32.

57. Sanders DB, Hoffman LR, Emerson J, et al. Return of FEV1 after pulmonary exacerbation in children with cystic fibrosis. Pediatr Pulmonol. 2010;45:127-34.

58. Antibiotic treatment for Cystic Fibrosis. Report of the UK Cystic Fibrosis Trust antibiotic Working Group. $3^{\text {rd }}$ edition May 2009. https://www.cysticfibrosis.org.uk/media/82010/CD_Antibiotic_ treatment_for_CF_May_09.pdf.

59. Griffith DE, Aksamit T, Brown-Elliott BA, et al. ATS Mycobacterial Diseases Subcommittee; American Thoracic Society; Infectious Disease Society of America. An official ATS/IDSA statement: diagnosis, treatment, and prevention of nontuberculous mycobacterial diseases. Am J Respir Crit Care Med. 2007;175: 367-416.

60. Sibley CD, Sibley KA, Leong TA, Grinwis ME, Parkins MD, Rabin HR, Surette MG. The Streptococcus milleri population of a cystic fibrosis clinic reveals patient specificity and intraspecies diversity. J Clin Microbiol. 2010;48(7):2592-4. doi:10.1128/ JCM.00414-10.

61. Smyth A, Lewis S, Bertenshaw C, et al. A case control study of acute renal failure in cystic fibrosis patients in the United Kingdom. Thorax. 2008;63:532-5.

62. Parmar JS, Nasser S. Antibiotic allergy in cystic fibrosis. Thorax. 2005;60:517-20. 